\title{
Temperature Variation Research on Industrial Bus Duct System by MATLAB and FEA
}

\author{
Thirumurugaveerakumar. S
}

\begin{abstract}
This paper displays a test, numerical and FEA thermal model of the heat transfer process in an industrial bus duct system. The examination incorporates a mechanical properties of various bus bar materials and bus bar configurations. At that point the calculation has been produced to anticipate the temperature ascend in the bus bars and furthermore to think about the sizes of bus bar materials like copper and aluminum and changes in air speeds for both the copper and aluminum bus bar materials utilizing MATLAB and FEA unfaltering state thermal investigation in ansys. The outcomes acquired from the MATLAB estimation and FEA investigation has been compared. It has been discovered that constrained convection - opposite wind current lessens the power misfortune because of thermal generation is likewise diminished in the bus bar conductors.
\end{abstract}

Keywords-Bus bar, Heat transfer, Current carrying capacity,convection.

\section{INTRODUCTION}

Electrical bus bar framework increases slightest need after the establishment, and the thermal and electrical stacking impact on this bar isn't been observed generally inside the exploration network. A scientific model of the electrical bus bar has been produced to think about the different sorts of electrical and thermal loading. For the examination, two kinds of electrical bus bar loads have been taken, i.e. one with light loading factor and another with substantial loading factor. The thermal investigation of these buses is considered in this work. Variables influencing the thermal examination of the bus bar are present conveying limit of the bus bar, step changes of the electric load and cross determination region of the bus bar

The inductance is additionally influenced by the presence of another current-carrying conductor in the region. $\mathrm{R}$ stage is arranged in the external layer, Y stage bus bar is kept in the middle of R and B bus bars. Consequently, from this it is comprehended that $\mathrm{Y}$ stage will have the increased effect of eddy current due to the magnetic field of $\mathrm{R}$ and $\mathrm{B}$ stage bus bars. Accordingly, flow of current through the Y stage bus bar is more prominent than the R stage bus bar and B stage bus bar. The primary objective in bus bar improvement is to increase the components ampacity and to the reduction of materials. Because of the flow of current in bus bars, occurrence of loss of power transform into heat. Thus, cooling is essential to ensure the performance at maximum level and reliability.

\section{BUS BAR CONFIGURATIONS}

The various bus bars may be organized in various configurations as shown in Figure1

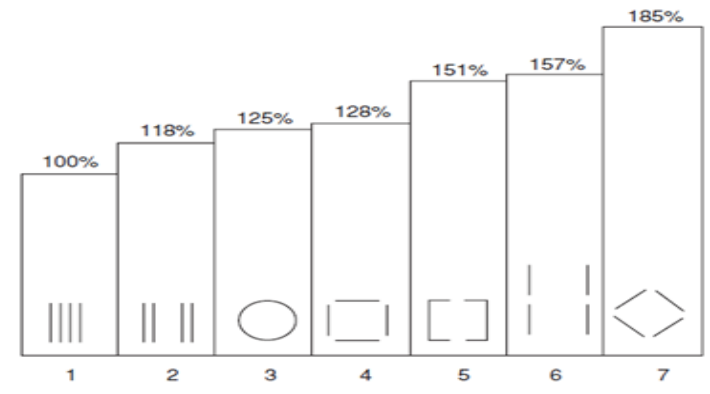

Fig. 1Bus bar configurations to improve heat dissipation and minimize skin effect

To enhance dissipation of heat and cut down the effect of skin and the effect of proximity. The progress made in the rating is an indication of the cooling and effect of skin with various configurations. At the point when various bars are stacked parallel, each bar shields the contiguous bar with reduction of dissipation of heat. Further, these bars together invlove in formation of large conductor and the current tends to concentration at the external surfaces alone because of skin effect. Thus, the inward surfaces share smaller current and the external surfaces share larger currents. An effort to enhance dissipation of heat and in reduction of effect of skin is taken in configurations other than parallel bars. It is ascertained that most conductors are at introduce adequately free and of high current carrying capability.

\section{MECHANICAL PROPERTIES OF THE BUS BAR}

It is vital to find out the mechanical quality of the busbar material in order to ensure that the material remains unblemished amid transport and get together and drooping is dodged regardless of extended working life at maximal temperature. Because of the cold working, there are the two upsides and downsides. Elongation is brought down While increase in tensile strength and hardness occurs.

Tensile Strength

The structure experiences change in increase of tensile strength to the request of $200-220 \mathrm{~N} / \mathrm{mm}^{2}$ because of hot working. Cross sectional area of a conductor and its tensile strength are inversely proportional due to the amount of cold work application is confined by cutting down the area which can be accomplished. 


\section{Proof Strength}

Production of a coveted measure of desired amount of permanent deformation in the metal is 'proof strength' which is an imperative manual for its mechanical properties. The stress at which a non-proportional elongation and indicated percentage (generally $0.2 \%$ ) of the occurrence of the original gauge length is called as the proof strength. arrangement of bus bar

The values are taken from the power house, which has the capacity of 2500A rating and 1500 KVA transformer substation shown in fig 2.In the transformer, the voltage is stepped down to $440 \mathrm{~V}$ for distribution to the load centres.

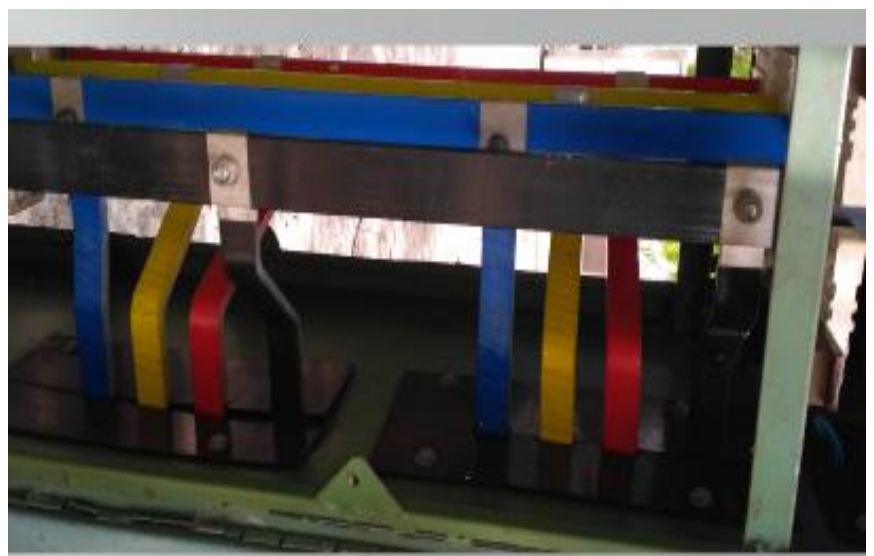

Fig.2 Bus bar panel arrangement in the power house

Experiments are conducted under natural convectional mode and with the forced convectional mode by keeping the airflow parallel and perpendicular to the bus bar.

Bus bar with 3 conductors per phase, as shown in Figure 3

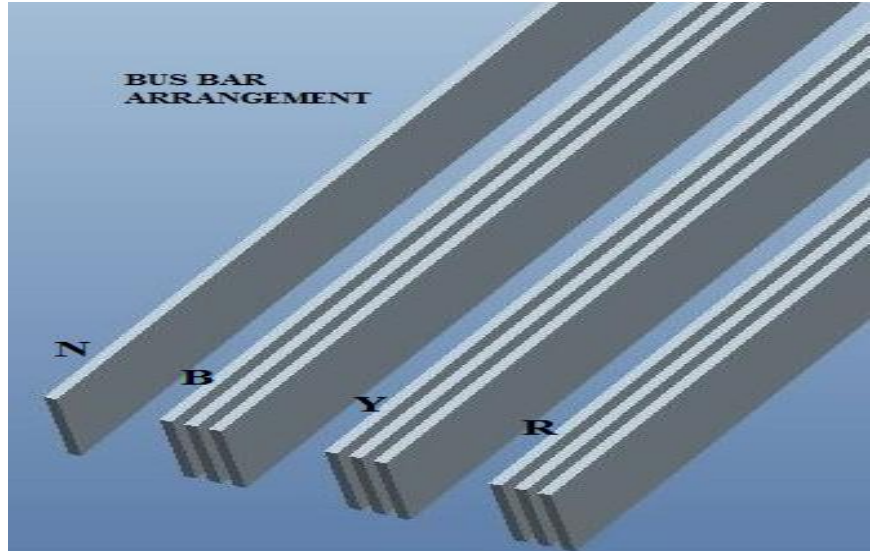

Fig.3Bus bar with 3 conductors per phase

From this arrangement, it is understood that $\mathrm{Y}$ phase will have the increased effect of eddy current due to the magnetic field of R and B phase bus bars. so, the steady state temperature in the phase $\mathrm{Y}$ is greater than other two phases.

\section{THERMAL MODEL OF BUS BAR}

The energy balance equation for bus bar is written as

$\rho c_{p} V \frac{d T}{d t}=I^{2} R(t)-h A_{s}\left(T-T_{\infty}\right)-\varepsilon \sigma A_{s}\left(T^{4}-T_{\infty}^{4}\right)$

Equation (1) is simplified as,

$$
\begin{array}{r}
\frac{d T}{d t}+\frac{h A_{s} \varepsilon \sigma A_{S}\left(T+T_{\infty}\right)\left(T^{2}+T_{\infty}^{2}\right)}{\rho C_{p} V}(T)= \\
\frac{I^{2} R(t)}{\rho C_{p} V}+\frac{h A_{s} \varepsilon \sigma A_{s}\left(T+T_{\infty}\right)\left(T^{2}+T_{\infty}^{2}\right)}{\rho C_{p} V}\left(T_{\infty}\right) \\
\frac{d T}{d t}+a(T)=C
\end{array}
$$

Where

$$
\begin{aligned}
& a=\frac{h A_{s} \varepsilon \sigma A_{s}\left(T+T_{\infty}\right)\left(T^{2}+T_{\infty}^{2}\right)}{\rho C_{p} V} ; C \\
& =\frac{I^{2} R(t)}{\rho C_{p} V} \\
& +\frac{h A_{s} \varepsilon \sigma A_{s}\left(T+T_{\infty}\right)\left(T^{2}+T_{\infty}^{2}\right)}{\rho C_{p} V}\left(T_{\infty}\right)
\end{aligned}
$$

Solution is,

$$
T_{i+1}=\frac{C}{a}\left(1-e^{-a t}\right)+T_{i}\left(e^{-a t}\right)(4)
$$

Thermal time constant of the bus bar material.

$$
\frac{T(t)-T_{1}}{T_{2}-T_{1}}=1-e^{\frac{t}{\tau}}
$$

The Thermal time constant equation is,

$$
\tau=\frac{\rho C_{p}\left(\frac{V}{A_{s}}\right)}{h+\varepsilon \sigma\left(T^{2}-T_{\infty}^{2}\right)\left(T-T_{\infty}\right)}(5)
$$

Convectional coefficient $(h)$ for the free convectional heat dissipation for vertical plate is calculated from the following Nusselt number correlation:

$$
N u_{x}=0.508 \operatorname{Pr}^{0.5}(0.952+P r)^{-0.25} G r_{x}^{0.25}
$$

Tthe forced convection cooling with air flow perpendicular to the bus bar, the correlations used is:

$$
N u_{x}=0.205 \operatorname{Re}_{x}^{0.731} \operatorname{Pr}^{\frac{1}{3}}(7)
$$

With air flow Parallel to the bus bar, the correlations used is:

$$
N u_{x}=0.664 \operatorname{Re}_{x}^{\frac{1}{2}} \operatorname{Pr}^{\frac{1}{3}}(8)
$$

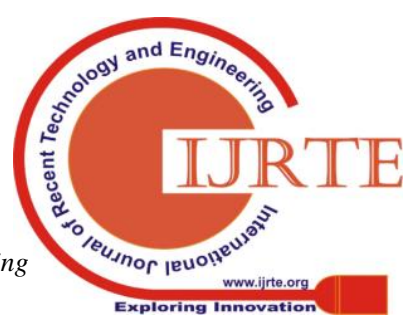


TABLE I Temperature variations of copper bus bar

\begin{tabular}{|c|c|c|c|c|c|c|}
\hline $\begin{array}{c}\text { Time } \\
\text { constant } \\
(\boldsymbol{\tau})\end{array}$ & \multicolumn{2}{|c|}{$\begin{array}{c}\text { Copper Bus bar } \\
\text { Temperature rise }\end{array}$} & \multicolumn{3}{c|}{$\begin{array}{c}\text { Aluminum Bus bar } \\
\text { Temperature rise }\end{array}$} \\
\cline { 2 - 7 } & $\begin{array}{c}\mathbf{1 0 0 m m} \\
\text { Width }\end{array}$ & $\begin{array}{c}\mathbf{5 0 m m} \\
\text { Width }\end{array}$ & $\begin{array}{c}\mathbf{3 5 m m} \\
\text { Width }\end{array}$ & $\begin{array}{c}\text { 100mm } \\
\text { Width }\end{array}$ & $\begin{array}{c}\mathbf{5 0 m m} \\
\text { Width }\end{array}$ & $\begin{array}{c}\mathbf{3 5 m m} \\
\text { Width }\end{array}$ \\
\hline $\mathrm{T}$ & 35.22 & 38.10 & 40.33 & 37.26 & 41.97 & 45.62 \\
\hline $2 \tau$ & 36.40 & 40.34 & 43.40 & 39.20 & 45.64 & 50.63 \\
\hline $3 \tau$ & 36.84 & 41.17 & 44.52 & 39.91 & 46.99 & 52.48 \\
\hline $4 \tau$ & 37.00 & 41.47 & 44.94 & 40.18 & 47.48 & 53.16 \\
\hline $5 \tau$ & 37.06 & 41.58 & 45.09 & 40.27 & 47.67 & 53.41 \\
\hline $6 \tau$ & 37.08 & 41.62 & 45.15 & 40.31 & 47.73 & 53.50 \\
\hline
\end{tabular}

TABLE II Temperature variations of aluminium bus bar

\begin{tabular}{|c|c|c|c|}
\hline $\begin{array}{c}\text { Time } \\
\text { consta } \\
\text { nt } \\
(\tau)\end{array}$ & $\begin{array}{c}\text { Temperature } \\
\text { variation under } \\
\text { natural } \\
\text { convection in } \\
\text { copper bus } \\
\text { bar }\left({ }^{\circ} \mathbf{C}\right)\end{array}$ & \multicolumn{2}{|c|}{$\begin{array}{c}\text { Temperature variation } \\
\text { under forced convection in } \\
\text { copper bus bar }\left({ }^{\circ} \mathbf{C}\right)\end{array}$} \\
\cline { 3 - 4 } & $\begin{array}{c}\text { Air flow } \\
\text { parallel to } \\
\text { bus bar axis }\end{array}$ & $\begin{array}{c}\text { Air flow } \\
\text { perpendicular } \\
\text { to bus bar } \\
\text { axis }\end{array}$ \\
\hline $\mathrm{T}$ & 60.77 & 38.46 & 35.22 \\
\hline $2 \tau$ & 71.35 & 40.83 & 36.40 \\
\hline $3 \tau$ & 75.25 & 41.71 & 36.84 \\
\hline $4 \tau$ & 76.68 & 42.03 & 37.00 \\
\hline $5 \tau$ & 77.21 & 42.15 & 37.06 \\
\hline $6 \tau$ & 77.40 & 42.19 & 37.08 \\
\hline $7 \tau$ & 77.47 & 42.21 & 37.09 \\
\hline & & & \\
\hline
\end{tabular}

TABLE III Temperature variation with different dimension

\begin{tabular}{|c|c|c|c|}
\hline $\begin{array}{c}\text { Time } \\
\text { constant } \\
(\boldsymbol{\tau})\end{array}$ & $\begin{array}{c}\text { Temperature } \\
\text { variation } \\
\text { under natural } \\
\text { convection in } \\
\text { aluminum bus } \\
\text { bar }\left({ }^{\circ} \mathbf{C}\right)\end{array}$ & $\begin{array}{c}\text { Temperature variation } \\
\text { under forced convection in } \\
\text { aluminum bus bar }\left({ }^{\circ} \mathbf{C}\right)\end{array}$ \\
\cline { 3 - 4 } & $\begin{array}{c}\text { Air flow } \\
\text { parallel to } \\
\text { bus bar } \\
\text { axis }\end{array}$ & $\begin{array}{c}\text { Air flow } \\
\text { perpendicular } \\
\text { to bus bar } \\
\text { axis }\end{array}$ \\
\hline $\mathrm{T}$ & 77.04 & 42.50 & 37.26 \\
\hline $2 \tau$ & 93.62 & 46.36 & 39.20 \\
\hline $3 \tau$ & 99.71 & 47.79 & 39.91 \\
\hline $4 \tau$ & 101.96 & 48.31 & 40.18 \\
\hline $5 \tau$ & 102.78 & 48.50 & 40.27 \\
\hline $6 \tau$ & 103.09 & 48.57 & 40.31 \\
\hline $7 \tau$ & 103.20 & 48.60 & 40.32 \\
\hline
\end{tabular}

\section{RESULT AND DISCUSSION}

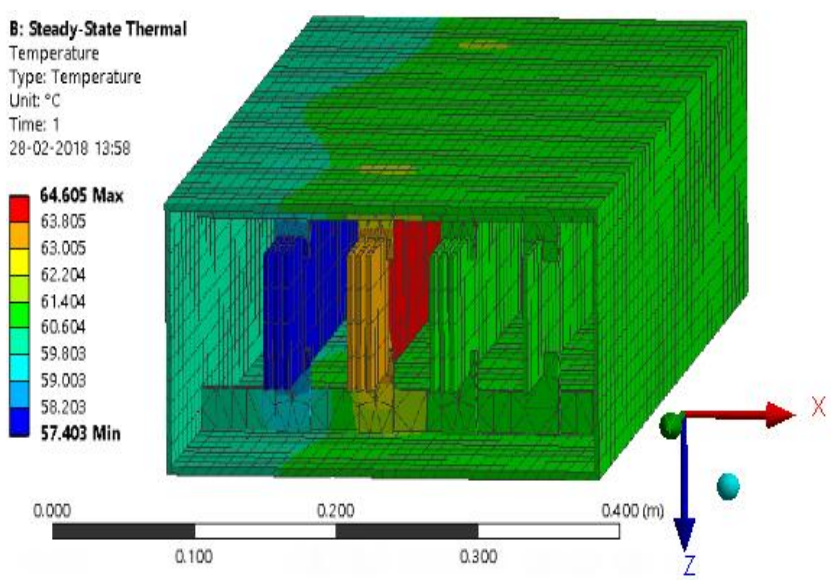

Fig.4 Steady state thermal analysis for copper bus bar under natural convection

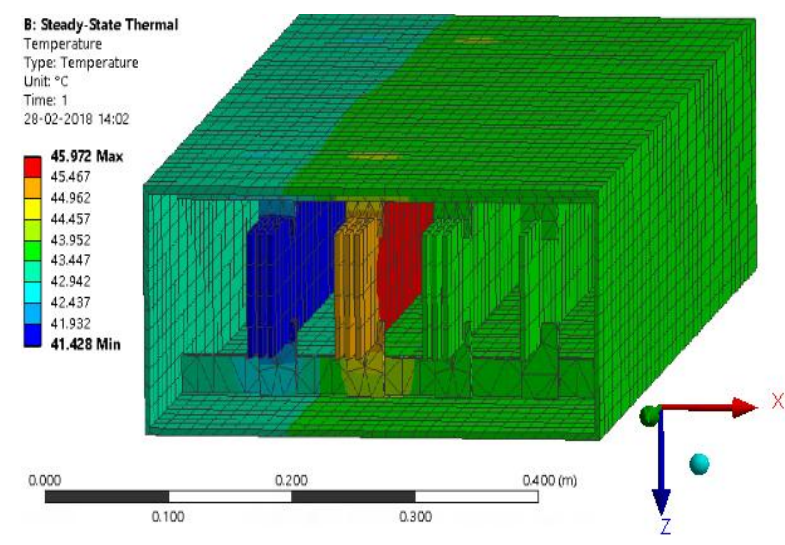

Fig. 5Steady state thermal analysis for copper bus bar under forced convection - Parallel air flow

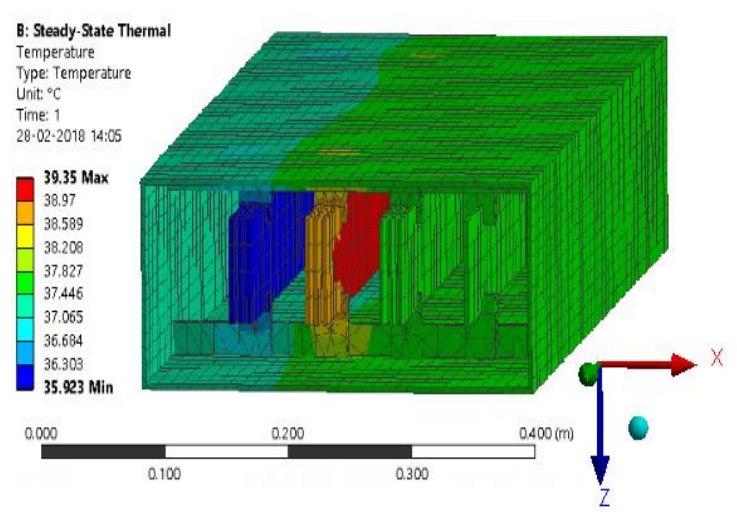

Fig. 6 Steady state thermal analysis for copper bus bar under forced convection - Perpendicular air flow

From the figures above 4,5 and 6 it is understood steady state thermal analysis for copper bus bar under natural convection, forced convection - parallel air flow and forced convection - perpendicular air flow. In these steady state thermal analysis the temperature attained in the copper bus bar under natural convection mode is $64^{\circ} \mathrm{C}$ and $57^{\circ} \mathrm{C}$ as maximum and minimum values. The maximum temperature is attained in the $\mathrm{Y}$ phase due to high current flows through the bus bar.

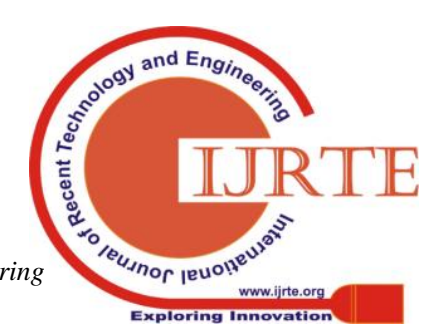


Compared to copper, aluminium material has low capacity of current carrying.

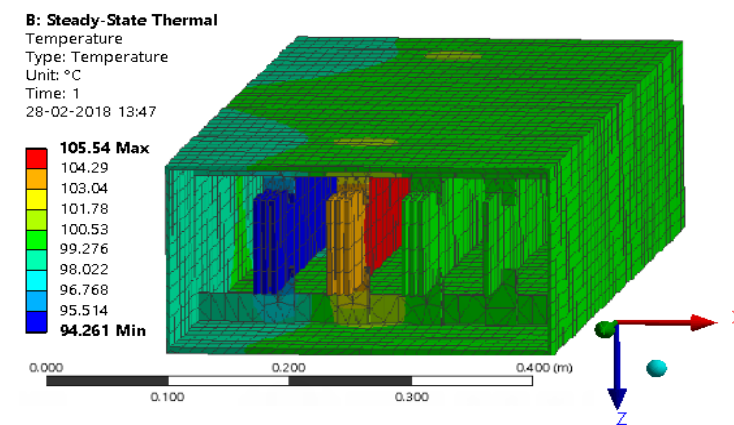

Fig.7 Steady state thermal analysis for Aluminum bus bar under natural convection

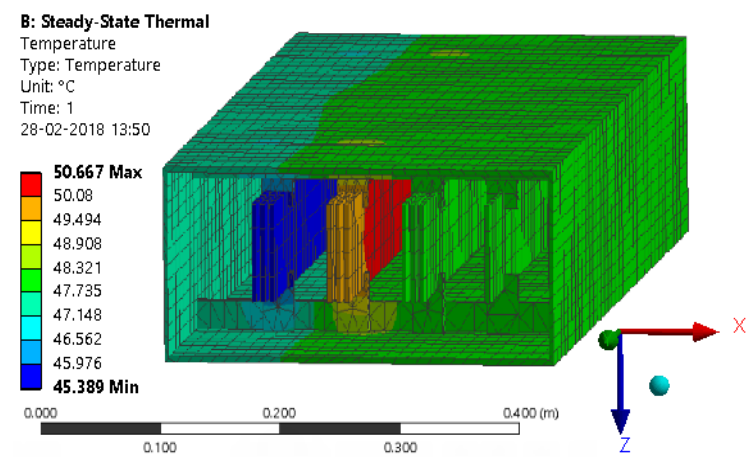

Fig.8 Steady state thermal analysis for Aluminum bus bar under forced convection - Parallel air flow

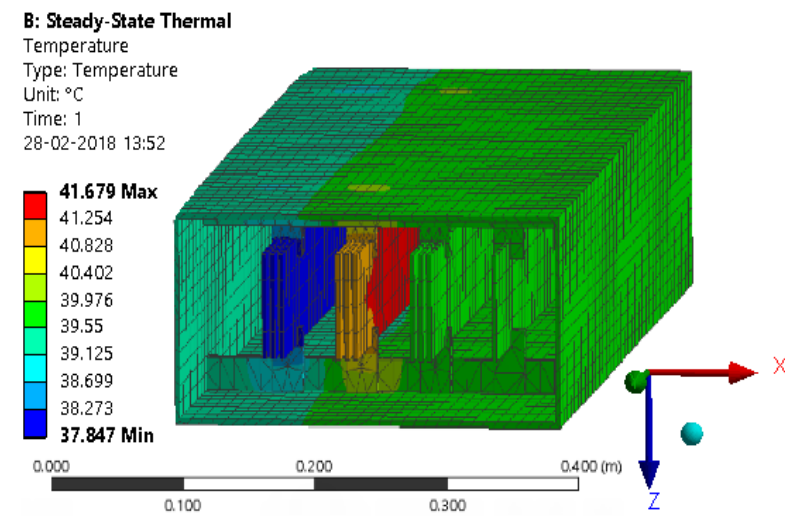

Fig.9 Steady state thermal analysis for Aluminum bus bar under forced convection - Perpendicular air flow

Figure 7, 8 and 9 shows steady state thermal analysis for aluminum bus bar under natural convection, forced convection - parallel air flow and forced convection perpendicular air flow. In these steady state thermal analysis the temperature attained in the aluminum bus bar under natural convection mode is $105^{\circ} \mathrm{C}$ and $94^{\circ} \mathrm{C}$ as maximum and minimum values. The maximum temperature is attained in the Y phase due to high current flows through the bus bar. The minimum temperature is attained in the $\mathrm{R}$ phase due to low current flows through the bus bar. To reduce the temperature rise in the bus bar, the forced convection mode is adapted.

During forced convection - parallel air flow, the temperature difference between the aluminum and copper bus bar is $5^{\circ} \mathrm{C}$ increased in aluminum bus bar. Then during perpendicular air flow, the temperature difference between the aluminum and copper bus bar is $2^{\circ} \mathrm{C}$ increased in aluminum bus bar. It displays that forced convection perpendicular air flow having a maximum amount of heat dissipation in both copper and aluminum bus bar.

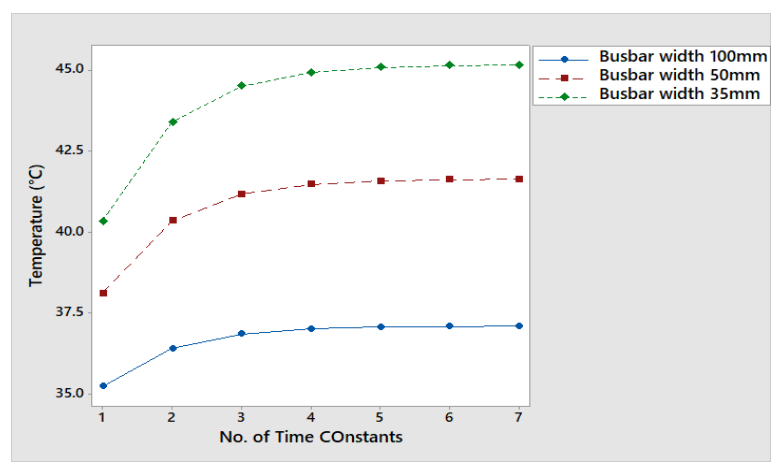

Fig. 10 Temperature variation with time constant for various standard sizes of copper bus bar

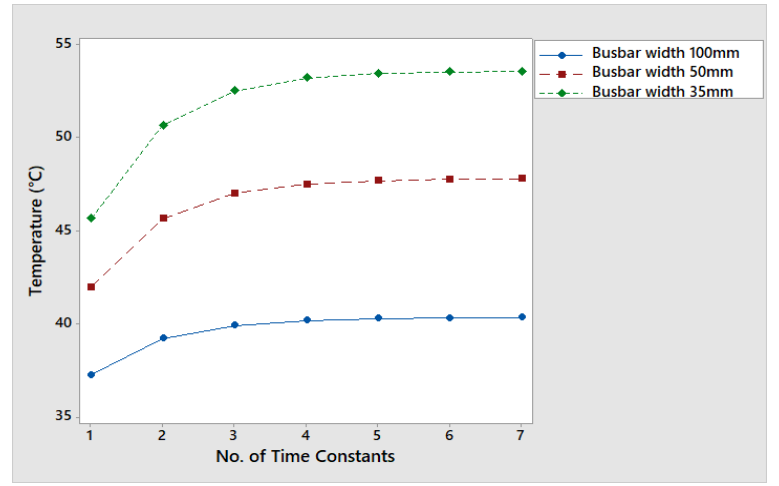

Fig. 11Temperature variation with time constant for various standard sizes of aluminum bus bar

To reduce the size of the bus bar, the algebraic equation developed from thermal model is solved using MATLAB by considering different standard sizes of $35 \mathrm{~mm}, 50 \mathrm{~mm}$ and $100 \mathrm{~mm}$ bus bars of copper and aluminum materials under the forced convection arrangement. Temperature variation of bus bar with the time constant for different sizes of bus bar for the air flow in the perpendicular direction to bus bar are shown in the fig 10 and 11 for copper and aluminum bus bars respectively.

In figure 10 copper bus bar for $100 \mathrm{~mm}$ width, steady state temperature is attained at $37^{\circ} \mathrm{C}$. If the width is reduced to $50 \mathrm{~mm}$ the steady state temperature increases by $10 \%$. Further, if the width of the bus bar is stepped down to the next standard size $(35 \mathrm{~mm})$ the steady state temperature increases by $18 \%$. Whereas in figure 11 aluminum bus bar for $100 \mathrm{~mm}$ width, steady state attains at $40^{\circ} \mathrm{C}$. If the width is reduced to $50 \mathrm{~mm}$ the steady state temperature is increased by $17 \%$. Moreover, if the width of the bus bar is stepped down next standard size $(35 \mathrm{~mm})$ the steady state temperature is increased by $32 \%$.

\section{CONCLUSION}

The perception of temperature variety for standard size copper bus bar is approved with hypothetical investigation

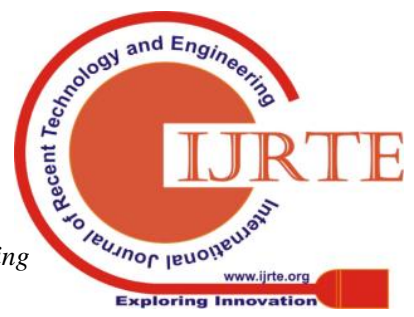


utilizing MATLAB. A calculation has been created to perform investigation to decide the temperature varieties in the bus bar of various materials of copper and aluminum utilizing MATLAB and FEA unfaltering state warm examination in ansys. In this manner in examination, temperature variety in the distinctive bus bar materials under common and forced convection mode are about same for both the MATLAB and FEA enduring state warm investigation. Here with forced convection cooling plan, the temperature variety of copper bus bar is watched and it is discovered that the temperature variety is well under the wellbeing range. Aluminum bus bar with diminished width estimate having the base temperature under forced convection - normal wind flow when contrasted with the copper transport bar of ordinary width measure under natural convection. So it is comprehended that aluminum bus bar with lessened sizes can be utilized as a part of place of copper under the constrained convection mode. Hence, forced convection warm dispersal with the wind current normal to the transport bar plan is ideal when aluminum replaces the copper bus bar.

\section{REFERENCES}

1. Bedkowski, Mateusz, et al. "Coupled numerical modelling of power loss generation in bus bar system of low-voltage switchgear." International Journal of Thermal Sciences 82 (2014): 122-129.

2. Bedkowski, M., et al. "2.5-D multilayer optimization of an industrial switch gear bus bar system." AppliedThermal Engineering 101 (2016): 147-155.

3. Bedkowski, M., et al. "Simulation of cooling enhancement inindustrial low-voltage switchgear usingvalidated coupled CFD EMAG model." International Journal of Thermal Sciences 111 (2017): 437-449.

4. Thirumurugaveerakumar, S., C. Velmurugan, andKavitha "Prediction of TemperatureVariations for Industrial Bus Duct System under Forced Convection Cooling with Various Aspect Ratios Using MATLAB". International Journal of Mechanical Engineering and Technology (IJMET) Volume 9,Issue 2, February 2018, pp. 734-741.

5. Thirumurugaveerakumar, S., M. Sakthivel,and S. Valarmathi. "Experimental and Analytical Study on the Bus Duct System for the Prediction of Temperature Variations Due To the Fluctuation of Load." Journal of Electrical Engineering and Technology 9.6 (2014): 2036-2041.

6. Thirumurugaveerakumar, S., Sakthivel, M., Rajendran, S.,"Experimentaland Analytical Study of Effect of Forced Convectional Cooling of Bus Duct System in the Prediction of Temperature Rise", International Journal of Advances in Engineering and Research 10 (2015), 21, pp.42202-42208.

7. Thirumurugaveerakumar, S., M. Sakthivel, and Deve V. Sharmila. "Prediction and comparison of size of the copper and aluminium bus duct system based on ampacity and temperature variations using MATLAB." Thermal Science 00 (2016): 153-153.

8. Coneybeer, Robert T., W. Z. Black, and R. A. Bush. "Steady-state and transient ampacity of bus bar." IEEE transactions on power delivery 9.4 (1994): 1822-1829.

9. Klimenta, Dardan O., et al. "An analytical algorithm to determine allowable ampacities of horizontally installed rectangular bus bars." Thermal Science 20.2 (2016): 717-730.

10. Arunkumar, R., and NagarajBalakrishnan. "Medical image classification for disease diagnosis by DBN methods." Pak J Biotechnol 15, no. 1 (2018): 107-110.

11. Ho, S. L., et al. "Calculations of eddy current, fluid, and thermal fields in an air insulated bus duct system." IEEE Transactions on Magnetics 43.4 (2007): 1433-1436.

12. Ho, S. L., et al. "A 3-D study of eddy current field and temperature rises in a compact bus duct system." IEEE Transactions on Magnetics 42.4 (2006): 987-990.

13. Ho, S. L., et al. "Calculations of eddy current, fluid, and thermal fields in an air insulated bus duct system." IEEE Transactions on Magnetics 43.4 (2007): 1433-1436.
14. Labridis, D. P., and P. S. Dokopoulos. "Electromagnetic forces in three-phase rigid bus bars with rectangular cross-sections." IEEE transactions on power delivery 11.2 (1996): 793-800.

15. Hwang, Chang-Chou, J. J. Chang, and Y. H. Jiang. "Analysis of electromagnetic and thermal fields for a bus duct system." Electric power systems research 45.1 (1998): 39-45.

16. Kim, JoongKyoung, et al. "Temperature rise prediction of EHV GIS bus bar by coupled magneto thermal finite element method." IEEE Transactions on Magnetics 41.5 (2005): 1636-1639. 